\title{
Fibroblast Growth Factor-1 Is a Mesenchymal Stromal Cell-Secreted Factor Stimulating Proliferation of Osteoarthritic Chondrocytes in Co-Culture
}

\author{
Ling Wu, ${ }^{1, *}$ Jeroen Leijten, ${ }^{1}$ Clemens A. van Blitterswijk, ${ }^{2}$ and Marcel Karperien ${ }^{1}$
}

Previously, we showed that mesenchymal stromal cells (MSCs) in co-culture with primary chondrocytes secrete soluble factors that increase chondrocyte proliferation. The objective of this study is to identify these factors. Human primary chondrocytes (hPCs) isolated from late-stage osteoarthritis patients were co-cultured with human bone marrow-derived MSCs (hMSCs) in pellets. Genome-wide mRNA expression analysis and quantitative polymerase chain reactions (qPCR) were used to identify soluble factors that were specifically induced in co-cultures. Immunofluorescent staining combined with cell tracking and enzyme-linked immunosorbent assay (ELISA) were performed to validate up-regulation at the protein level and to identify the cellular origin of the increased proteins. Chemical blockers and neutralizing antibodies were used to elucidate the role of the identified candidate genes in co-cultures. A number of candidate factors were differentially regulated in co-cultures at the mRNA level. Of these, fibroblast growth factor-1 (FGF-1) mRNA and protein expression were markedly increased in co-cultures predominantly due to up-regulated expression in MSCs. Blocking of FGF signaling in co-culture pellets by specific FGF receptor inhibitors or FGF-1 neutralizing antibodies completely blocked hPCs proliferation. We demonstrate that MSCs increase FGF-1 secretion on co-culture with hPCs, which, in turn, is responsible for increased hPCs proliferation in pellet co-cultures.

C ARTILAGE REPAIR IS AMONG the key targets of regenerative medicine. Several stem cell-based therapies have been proposed to treat cartilage defects, rheumatic arthritis, osteoarthiris (OA), and other joint diseases. These therapeutic strategies include implantation or injection of mesenchymal stromal cells (MSCs) in the diseased joint or bone marrow stimulation techniques such as micro fracture. These procedures rely on cellular interactions between MSCs and native cells in the joint [1-4]. Recent studies showed that intra-articularly injected MSCs can reduce incidence and severity of arthritis in animal model by inducing immune tolerance [5]. Further investigations showed that MSCs are capable of inducing hyporesponsiveness of T-lymphocytes and of expressing antiinflammatory mediators in macrophages [6,7]. Besides immuno-suppressive effects, intra-articularly injected MSCs were also reported to inhibit thickening of the synovium and to protect against cartilage destruction in a mouse OA model [8]. However, with the cellular interactions between MSCs and native chondrocytes receiving less attention [9], the molecular mechanism of interactions between MSCs and native chondrocytes is poorly understood [10]. In order to maximize the benefits of stem cell therapy, these cellular interactions need to be clarified.

Previous reports showed that cartilage matrix formation was increased in co-cultures of human primary chondrocytes (hPCs) with MSCs compared with monocultures [11,12]. Further investigations revealed that the inductive effects of MSCs on cartilage formation were predominantly due to stimulation of hPCs proliferation in the co-culture pellets [13]. This effect was defined as a trophic effect of MSCs in cartilage regeneration. Additional studies showed that this trophic effect of MSCs in hPCs co-cultures was independent of culture conditions and their source [14]. Regarding the underlying mechanism of MSCs' trophic role in tissue regeneration, it was reported that a number of growth factors and cytokines secreted by MSCs could be of importance. It was reported that conditioned medium (CM) of MSCs promoted wound healing in a scratch model in vitro by affecting cell migration and extracellular matrix formation [15]. Moreover, CM of amniotic fluid-derived MSCs accelerated wound healing in a mouse excision wound model [16]. In

Departments of ${ }^{1}$ Developmental BioEngineering and ${ }^{2}$ Tissue Regeneration, MIRA-Institute for Biomedical Technology and Technical Medicine, University of Twente, Enschede, The Netherlands.

*Current affiliation: Department of Orthopaedic Surgery, Orthopedic Hospital Research Center, David Geffen School of Medicine, University of California at Los Angeles, Los Angeles, California. 
our own study, pellets of bovine chondrocytes cultured in MSCs conditioned proliferation medium showed a higher proliferation rate than cells cultured in non-CM [13]. Nevertheless, publications pinpointing the trophic role to a specific factor are scarce $[17,18]$.

In this study, we used microarray experiments to investigate the differentially expressed genes in co-culture (MSCs and hPCs) and mono-culture pellets (MSCs or hPCs separately). A number of secreted factors were found to be up-regulated in co-culture pellets. Further studies identified fibroblast growth factor-1 (FGF-1) as a prime candidate for an MSC secreted factor that promotes the proliferation of hPCs in co-cultures of MSCs and hPCs.

\section{Materials and Methods}

\section{Cell culture and expansion}

The use of human material has been approved by a local Medical Ethics Committee. Macroscopically healthy looking cartilage was obtained from knee or hip biopsies of patients with end-stage osteoarthritis who were undergoing total knee or hip replacement. HPCs were isolated as previously described [19]. In short, cartilage was digested for 20-22 h in collagenase type II (0.15\% Worthington) in DMEM supplemented with penicillin $(100 \mathrm{U} / \mathrm{mL})$ and streptomycin $(100 \mathrm{mg} / \mathrm{mL})$. hPCs were then cultured in chondrocyte proliferation medium (DMEM supplemented with 10\% FBS, $1 \times$ nonessential amino acids, $0.2 \mathrm{mM}$ Ascorbic acid 2phosphate, $0.4 \mathrm{mM}$ proline, $100 \mathrm{U} / \mathrm{mL}$ penicillin, and $100 \mu \mathrm{g} / \mathrm{mL}$ streptomycin). Bovine primary chondrocytes (bPCs) were isolated from full-thickness cartilage of knee biopsies from cows of $\sim 6$ months old with the same protocol as hPCs. Bone marrow MSCs were separated from human bone marrow aspirates as previously described [20]. Briefly, aspirates $(100 \mu \mathrm{L})$ were mixed with $900 \mu \mathrm{L}$ of red cell lysing buffer for 5-10 min on ice. The mononuclear cell fraction was counted. Cells were plated at a density of $50,000 / \mathrm{cm}^{2}$ in a culture flask in MSC proliferation medium ( $\alpha$-MEM, supplemented with $10 \%$ fetal bovine serum, 1\% L-glutamin, $0.2 \mathrm{mM}$ ascorbic acid, $100 \mathrm{U} / \mathrm{mL}$ penicillin, $10 \mu \mathrm{g} / \mathrm{mL}$ streptomycin, and $1 \mathrm{ng} / \mathrm{mL}$ bFGF), plus $1 \%$ heparin. Medium was refreshed every 3-4 days until confluence. All reagents used for cell culture were purchased from Gibco, Invitrogen, unless otherwise stated. Common chemicals were purchased from Sigma-Aldrich.

\section{Cell tracking with organic fluorescent dyes}

The organic fluorescent dye, CM-DiI (Molecular Probes) was used for cell tracking in co-cultures. HPCs were labeled according to the manufacturer's protocol. HPCs applied in co-culture experiments are shown as red cells.

\section{Co-culture of $h P C s$ and $h M S C s$}

For co-culture of hPCs or bPCs and hMSCs, 40,000 chondrocytes and 160,000 hMSC (ratio of PC:hMSCs=1:4) were seeded in one well of a round bottom ultralow attachment of a 96-well plate in chondrocyte proliferation medium and centrifuged for $3 \mathrm{~min}$ at 2,000 rpm. Medium was refreshed twice a week. Cell pellets were cultured for 2 days before RNA isolation and 5-ethynyl-2'-deoxyuridine (EdU) staining.

\section{EdU labeling and staining}

Cell proliferation in pellets was examined with the Click$\mathrm{iT}^{\circledR}$ EdU Imaging Kit (Molecular Probes). Cell pellets were cultured in chondrocyte proliferation medium. EdU was added to the culture media at a concentration of $10 \mu \mathrm{M}, 24 \mathrm{~h}$ before harvesting the samples. Cell pellets were then washed with PBS and fixed with $10 \%$ formalin for $15 \mathrm{~min}$. Samples were embedded in cryomatrix, and cut into $10 \mu \mathrm{m}$ sections with a cryotome (Shandon). Sections were permeabilized and stained for EdU with Alexa 488 cocktail. Nuclei were counterstained with Hoechst 33342.

\section{RNA isolation and quantitative PCR}

Gene expression analysis was performed as described earlier [21]. RNA samples were isolated with the Nucleo$\operatorname{Spin}^{\circledR}$ RNA II Kit (Macherey-Nagel). For quantitative polymerase chain reactions (qPCR), $1 \mu \mathrm{g}$ of total RNA was reverse transcribed into cDNA using the iScript cDNA Synthesis kit (Bio-Rad). qPCR was performed on cDNA samples by using the iQ SYBR Green Supermix (Bio-Rad). PCR reactions were carried out on MyiQ2 Two-Color RealTime PCR Detection System (Bio-Rad). For each reaction, a melting curve was generated to test primer dimer formation and nonspecific priming. The primers for real-time PCR are listed in Supplementary Tables S1 and S2 (Supplementary Data are available online at www.liebertpub.com/scd). Relative expression was calculated using the double delta $\mathrm{Ct}$ method. GAPDH was used for normalization.

\section{Microarray processing and statistical analysis}

For a microarray study, equal number of cells from three hPCs donors was pooled. The pooled cells were used in pellet monocultures $(n=3)$ and in co-cultures with three distinct donors of hMSCs. RNA was also isolated from the three MSC donors cultured in pellets individually. RNA samples were prepared as previously described. NuGEN Ovation PicoSL WTA System kit followed by Encore BiotinIL module was used to generate biotinylated sscDNA starting from $50 \mathrm{ng}$ total RNA. $750 \mathrm{ng}$ of the obtained samples was hybridized onto Illumina HumanHT-12 v4 Expression BeadChips. Samples were scanned using the Illumina iScan array scanner. Gene expression profiling was performed using Illumina's Genomestudio v. 2010.3 software with the default settings advised by Illumina. The raw fluorescence intensity values were normalized by applying quantile normalization. Differential gene expression was analyzed using the commercial software package Genespring, version 11.5.1. (Agilent Technologies). Genes with at least a twenty-percent difference between observed and expected values were selected and tested for significance using a one-way analysis of variance (ANOVA) with a Benjamini-Hochberg FDR correction and Tukey honestly significant difference (HSD) post hoc test using a cut-off rate of $P \leq 0.05$. The expected value of gene expression was defined as $80 \%$ of the expression of the gene in monoculture pellets of hMSCs added to $20 \%$ of the expression of the gene in monoculture pellets of hPC, both of which were determined by microarray analysis assuming that gene expression was not influenced by the co-culture. The observed values of gene expression reflected the actually expression level of one gene measured in the microarray experiment (Supplementary Fig. S1). Changes in gene expression in 
annotated canonical pathways and bio-functions were visualized using ingenuity pathway analysis software (Ingenuity Systems). Search Tool for the Retrieval of Interacting Genes/ Proteins (STRING) was used to investigate the predicted interaction network [22]. Clusters were formed using a k-means clustering algorithm.

\section{Immunofluorescent staining}

At day 2 after seeding, co-culture pellets were harvested for immunofluorescent staining. Cryo-sections from cell pellets were prepared as previously described. Sections were permeabilized and blocked in PBS containing 0.5\% Triton-X 100 and $0.5 \%$ bovine serum albumin for $15 \mathrm{~min}$ at room temperature. Slides were subsequently incubated overnight at $4^{\circ} \mathrm{C}$ with a goat polyclonal antibody against FGF-1 (R\&D System). Subsequently, slides were washed and incubated with a secondary antibody conjugated to Alexa 488 (Molecular Probes), and nuclei were counterstained with 4,6-diamidino-2-phenylindole (DAPI; Molecular Probes).

\section{Image acquisition and analysis}

All fluorescent images were taken with a BD pathway 435 confocal microscope (BD Biosciences). Separated images were captured at the green channel (Alexa 488), red channel (DiI), and blue channel (Hoechst 33342). ImageJ software [23] was used for cell counting. Briefly, a threshold was set to avoid artifacts manually. Then, numbers of green cells, red cells, green + red cells, and total cells were counted by running plug-ins written with macro language (available on request). Values represent the mean \pm standard error of at least three biological replicates.

\section{Collection of CM}

$\mathrm{CM}$ was collected by incubating chondrocyte proliferation medium with pellets of mono-cultures (hMSCs or hPCs) or co-cultures. Concentrations of FGF-1 in such media were measured without any treatment. CM was also obtained by incubating DMEM with hMSCs cultured in the monolayer at $90 \%$ confluency for $48 \mathrm{~h}$. CM was then passed through a $0.22 \mathrm{~mm}$ filter and stored at $-20^{\circ} \mathrm{C}$. On usage, $\mathrm{CM}$ was thawed, put in Amicon Ultra-15 Centrifugal Filter Units (Millipore) with a cutoff value of 3,000 dalton Nominal Molecular-Weight Limit, and centrifuged at 4,000 $\mathrm{g}$ for $40 \mathrm{~min}$. The concentrated solute (still named (CM) was first applied to enzyme-linked immunosorbent assay (ELISA) to a test concentration of FGF-1; then, it was used to supplement chondrocyte proliferation medium containing FBS and used to culture hPCs pellets.

\section{ELISA assay}

The concentrations of human FGF-1 in the CM of co-culture or mono-culture pellets or hMSC 2D cultures were determined by a human FGF-1 ELISA kit (R\&D system). Absorbance was measured on a plate reader at a wavelength of 450 and $550 \mathrm{~nm}$. The $450 \mathrm{~nm}$ values were subtracted by the $550 \mathrm{~nm}$ values for correction of the optical imperfections in the microplates.

\section{Statistical analysis}

Differences between culture conditions of MSCs and hPCs were examined for statistical significance with one-way
ANOVA followed by Tukey HSD Test. Comparisons between hMSCs and hPCs in the same conditions were made by using the Student's $t$-test. $P$ values of $<0.05$ were considered significant.

\section{Results}

\section{Co-culture enhances proliferation of hPCs isolated from late-stage OA patients}

Previously, we reported that proliferation of chondrocytes was enhanced in a xenogenic co-culture system of bovine chondrocytes and hMSCs [13]. In this study, we examined the proliferation of hPCs in a fully human co-culture system with hPCs isolated from osteoarthritic knee or hip joints. Since the bPC proliferated mostly at day 2 after establishing the coculture, we analyzed proliferation in fully human co-culture pellets at day 2 by measuring EdU incorporation. To distinguish hMSCs from hPC, the latter cells were labeled with the membrane-bound fluorescent tracer CM-DiI (red). As shown in Fig. 1A, EdU-positive cells were predominantly found at the periphery of the cell pellets in which the red labeled hPCs resided. The percentage of EdU-positive hPCs and EdUpositive hMSCs in the co-cultures was determined. Our results showed that co-culture significantly stimulated EdU incorporation in hPCs $(P<0.01)$ but not in hMSCs (Fig. 1B).

\section{Microarray study identifies a group of genes regulated by the interactions between MSCs and $h P C s$}

Since after $48 \mathrm{~h}$ in co-culture, hPCs proliferation was strongly increased we chose this time point for microarray analysis to identify genes that are regulated by the interaction between MSCs and hPC. In addition, based on our previous data [13], the beneficial effects of co-culture could be very well shown at a ratio of 4:1 (MSC:hPCs). Total RNA was isolated from three independent experiments, each with three experimental conditions: monoculture pellet of MSCs, co-culture pellet of MSCs and hPCs (ratio 4:1), and monoculture pellets of hPC. Each RNA sample was hybridized to (Illumina HumanHT-12 v4 Expression BeadChips). After data normalization, the ratio between observed gene expression as determined by the microarray experiment and expected values of gene expression was calculated (Supplementary Fig. S1) and significantly changed genes $(P \leq 0.05$, after one-way ANOVA with a Benjamini-Hochberg FDR correction and Tukey HSD post hoc test), deviating more than $20 \%$ from the expected value that had been selected. Hierarchical cluster analysis using the significantly changed genes showed a higher degree of similarity in gene expression profile with hMSC mono-culture pellets than with hPCs mono-culture pellets (Fig. 2A). Figure 2B shows a global comparison between observed values and expected values of each gene analyzed in the microarray experiment in co-culture pellets. Using a threshold for up-regulated genes of Ratio ${ }_{\mathrm{O} / \mathrm{E}}>1.2$ and a threshold for down-regulated genes of Ratio $_{\mathrm{O} / \mathrm{E}}<0.8$, the expression of 180 genes was positively regulated by co-culture, while the expression of 93 genes was negatively regulated by co-culture, respectively (Fig. 2A and Supplementary Table S3 for a full list of these differentially regulated genes). The expression of the majority of genes 

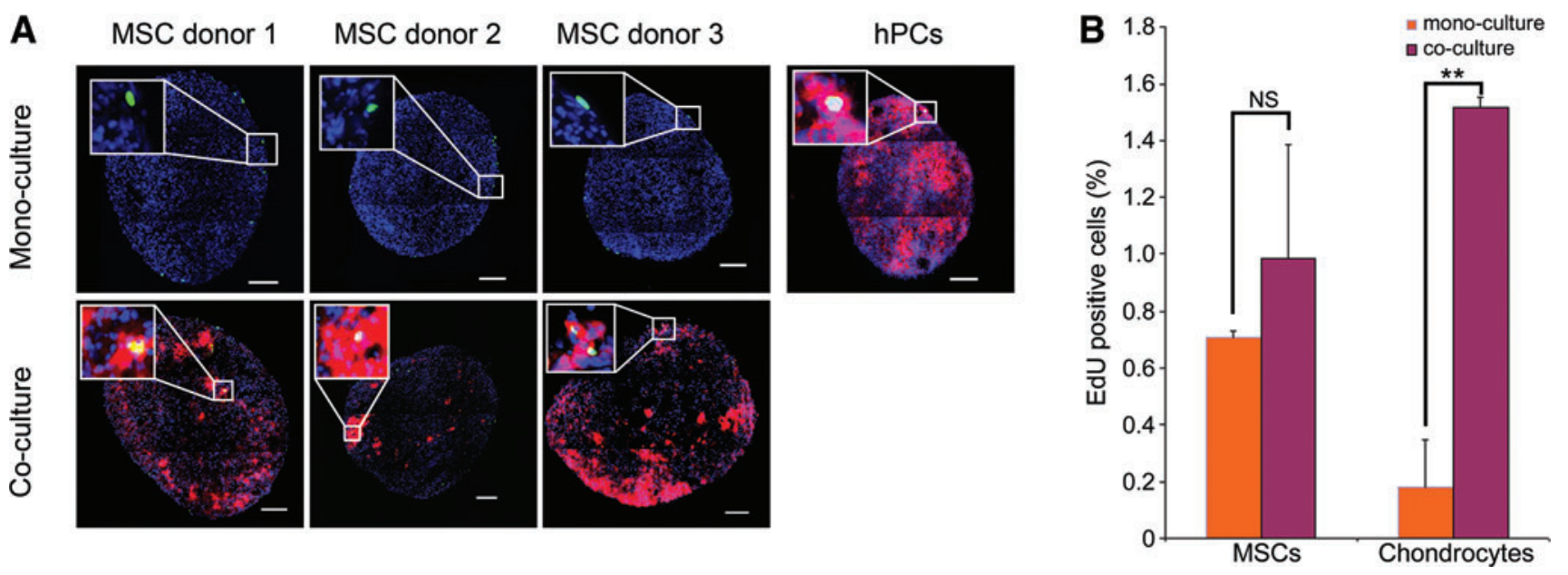

FIG. 1. Co-culture increases proliferation of hPCs. (A) EdU staining of pellets at day 2. hPCs were labeled with CM-DiI (red). EdU incorporation into newly synthesized DNA was visualized by Alexa 488 (green). Double-labeled cells indicate EdUpositive chondrocytes. Nuclei were counterstained with Hoechst 33342 (blue). A representative picture of each condition is shown. The upper panel shows overviews of pellets, while the lower panel shows magnified pictures of the boxed area. Scale bar $=100 \mu \mathrm{m}$. (B) Quantification of EdU-positive cells in (A) in MSCs and hPC using cell tracking with CM-Dil. Data represent the mean EdU-positive MSCs of three donors and hPC in monoculture or in co-culture (ratio MSC vs. hPC: 4:1), with each measured at least triplicate. Values shown are mean \pm standard deviation (S.D.). $P$ values were calculated by Student's $t$-test. ${ }^{* *} P<0.01$. EdU, 5-ethynyl-2'-deoxyuridine; hPCs, human primary chondrocytes; MSCs, mesenchymal stromal cells; NS, nonsignificant. Color images available online at www.liebertpub.com/scd

(22835) was not influenced by the co-culture and felt in the region between the two thresholds (gray points). qPCR analysis of 12 up-regulated and 5 down-regulated genes confirmed the direction of change in gene expression based

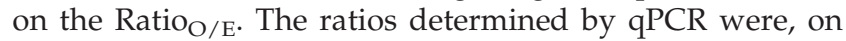
average, slightly higher or lower for up-regulated and down-regulated genes, respectively (Fig. 2C). The list of 180 up-regulated genes was then imported into ingenuity pathway analysis software to examine whether the changes in gene expression could be annotated to canonical pathways and bio-functions. Signaling pathways such as cellular growth and proliferation in molecular and cellular function pathways (Supplementary Fig. S2), cyclins, and cell-cycle regulation in canonical pathways (Supplementary Fig. S3) and the skeletal and muscular system development in physiological system development/function pathways (Supplementary Fig. S4) were significantly changed. Activation of these signaling pathways was in line with our observations of increased proliferation and matrix formation in co-cultures. The genes analyzed by ingenuity pathway analysis software were listed in Supplementary Table S4. We next analyzed the differentially expressed genes using the Search Tool for the Retrieval of Interacting Genes/Proteins to investigate possible interaction networks of genes/proteins (Fig. 3A). Four main clusters of interacting genes were identified. Two of these clusters were related to extracellular matrix and were centered on COMP (red cluster) and COL4A1 (green cluster), respectively. In line with increased EdU incorporation in co-culture pellets, 1 cluster contained intracellular cell-cycle regulators, such as CCND1, -2 , and -3 . The fourth cluster contained two secreted growth factors FGF-1 and BMP-2, both of which are established modulators of chondrocyte proliferation and/or matrix production [24-26].

\section{FGF-1 expression and secretion is up-regulated in co-culture pellets}

Since pellet co-culture with MSCs also increases chondrocyte proliferation in a xenogenic co-culture model of hMSCs and bPC, we studied differential expression of a selected set of genes in this model. By using species-specific PCR, it was possible to attribute the change in gene expression to either one of the two cell types. Most of the tested bovine genes, including BMP-2 and FGF-1, were expressed at higher levels in co-culture pellets than in bPC mono-cultures (Fig. 3B). Human-specific qPCR demonstrated a slight trend to increased expression of most genes in co-culture pellets compared with hMSCs mono-culture pellets (Fig. 3C). To quantify gene expression in each of the two cell types in coculture pellets, we next used cross-species GAPDH for normalization. As shown in Fig. 3D, FGF-1 and CCND1 were the only two genes predominantly expressed by hMSCs. Since it was previously shown that chondrocyte proliferation in coculture pellets is stimulated by an MSC secreted factor [13] and CCND1 is an intracellular regulator, FGF-1 was selected for further experimentation. We then examined the expression of FGF-1 in co-culture pellets of hMSCs and hPC (4:1 ratio) in which the hPCs were labeled red and FGF-1 was stained in green (Fig. 4A). FGF-1 staining resided predominantly in a ring at the periphery of the cell pellets in which the hPCs also resided. Overlay of fluorescent images demonstrated a few hPCs that were staining positive for FGF-1, but most FGF-1 staining was found in nonlabeled MSCs. This was confirmed by a quantitative analysis of the fluorescent images (Fig. 4B). In agreement with the seeding ratio of the labeled hPCs and hMSCs, $18.3 \% \pm 1.3 \%$ of the counted cells were labeled red. On average, $72 \%$ of the area stained for FGF-1 coincided with nonlabeled MSCs, identifying the 

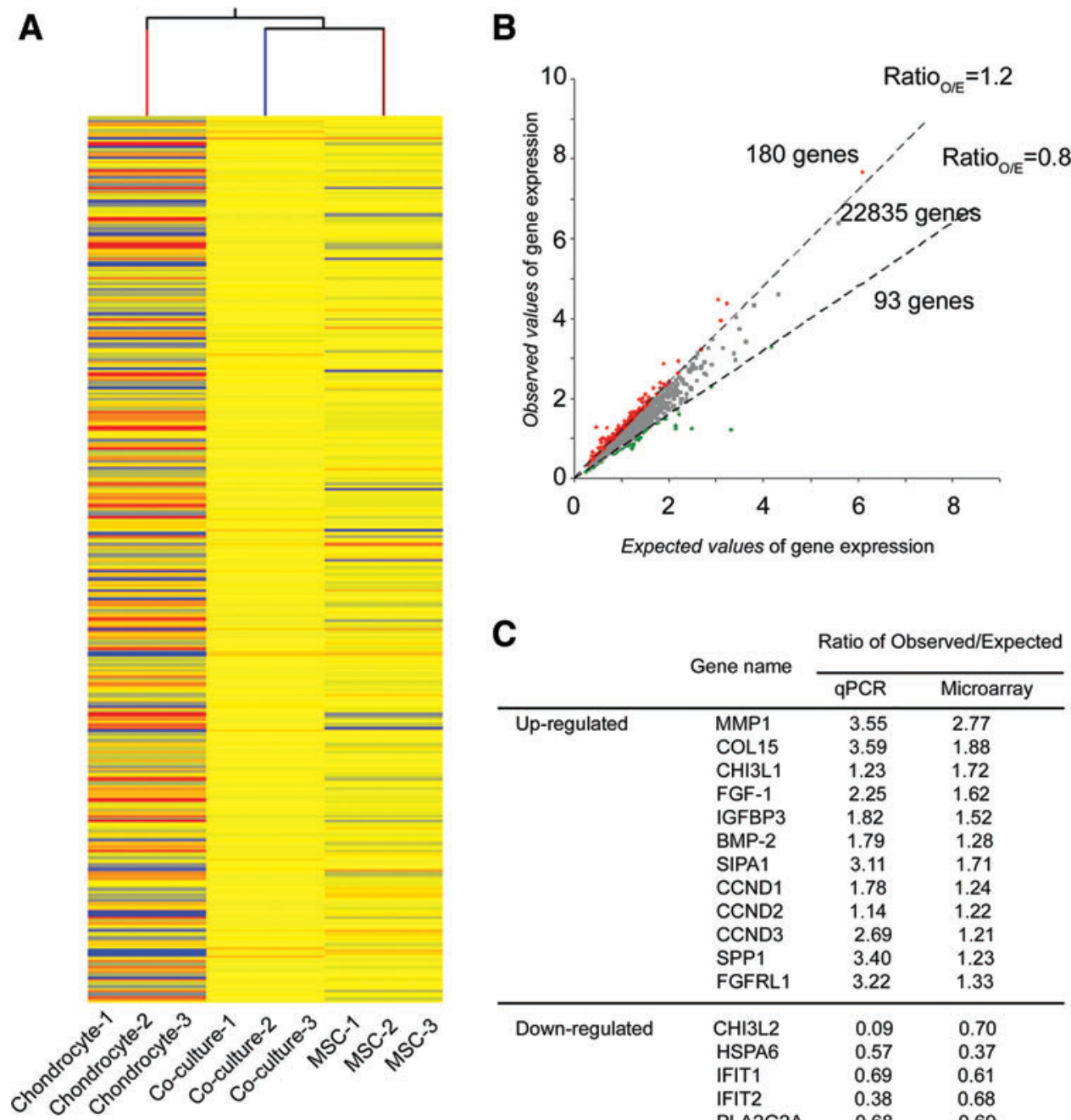

\begin{tabular}{llcc} 
& & \multicolumn{2}{c}{ Ratio of Observed/Expected } \\
\cline { 3 - 4 } & & & \\
\cline { 3 - 4 } & & & \\
& & qPCR & Microarray \\
\hline Up-regulated & MMP1 & 3.55 & 2.77 \\
& COL15 & 3.59 & 1.88 \\
& CHI3L1 & 1.23 & 1.72 \\
& FGF-1 & 2.25 & 1.62 \\
& IGFBP3 & 1.82 & 1.52 \\
& BMP-2 & 1.79 & 1.28 \\
& SIPA1 & 3.11 & 1.71 \\
& CCND1 & 1.78 & 1.24 \\
& CCND2 & 1.14 & 1.22 \\
& CCND3 & 2.69 & 1.21 \\
& SPP1 & 3.40 & 1.23 \\
& FGFRL1 & 3.22 & 1.33 \\
\hline \multirow{2}{*}{ Down-regulated } & CHI3L2 & 0.09 & 0.70 \\
& HSPA6 & 0.57 & 0.37 \\
& IFIT1 & 0.69 & 0.61 \\
& IFIT2 & 0.38 & 0.68 \\
& PLA2G2A & 0.68 & 0.69
\end{tabular}

FIG. 2. Global gene expression analysis in co-culture pellets. (A) RNA samples were isolated at $48 \mathrm{~h}$ and applied to a microarray study. Hierarchical clustering analysis shows the comparison of gene expression profiles in mono-cultures and cocultures. The gene expression pattern in co-cultures resembles more the gene expression patterns in MSCs than in hPCs. (B) Observed gene expression levels as determined by microarray analysis in co-cultures of hMSCs and hPCs are plotted against expected gene expression levels defined as $80 \%$ of the expression of the respective gene in MSC monocultures added to $20 \%$ expression of the gene in hPCs monocultures. Dashed lines indicate thresholds for up- (>1.2-fold) and down-regulated gene expression $(<0.8$-fold) compared with the calculated expected values. In red, genes are depicted with deviate $>1.2$-fold from the expected ratio. In green, genes that deviate $<0.8$-fold from the expected ratio are depicted. (C) Expression levels of differentially regulated genes in mono-cultures and co-culture pellets were validated by qPCR. The expression values obtained from qPCR were also calculated for the ratio of observed values and expected values. qPCR, quantitative polymerase chain reactions. Color images available online at www.liebertpub.com/scd

MSCs as the most likely predominant source of FGF-1 expression in co-culture pellets. This was in line with the mRNA expression data presented in Fig. 3B-D. Remarkably, MSCs staining positive for FGF-1 were predominantly found in the close vicinity of red-labeled hPCs, while staining in more distant MSCs was considerably lower or absent, providing support for the notion that the interaction between the hPCs and hMSCs increased FGF-1 expression in the latter cells. Besides FGF-1 mRNA expression, we also tested the levels of active FGF-1 protein in the CM (un-concentrated) of co-culture or mono-culture pellets. Our data showed that $\mathrm{CM}$ of co-culture pellets, but not of mono-culture pellets, contained considerable cells (Fig. 4C).

\section{Blocking of the FGF signaling pathway inhibits proliferation of $\mathrm{hPCs}$ in co-culture pellets}

To study the role of increased FGF-1 expression and secretion in co-culture pellets, two small molecules (PD166866 and PD173074), both of which were $500 \mathrm{nM}$ in the culture medium, were used to block FGF receptors in co-culture or mono-culture pellets (Fig. 5A). PD-166866 is a selective inhibitor of the FGF receptor 1 (FGFR1), while PD 173074 is a FGF receptor 3 (FGFR3) inhibitor. EdU assays were performed to investigate the proliferation of cells in co-culture pellets. Quantification of EdU-positive cells indicated that both inhibitors decreased the proliferation of both MSCs (Fig. 


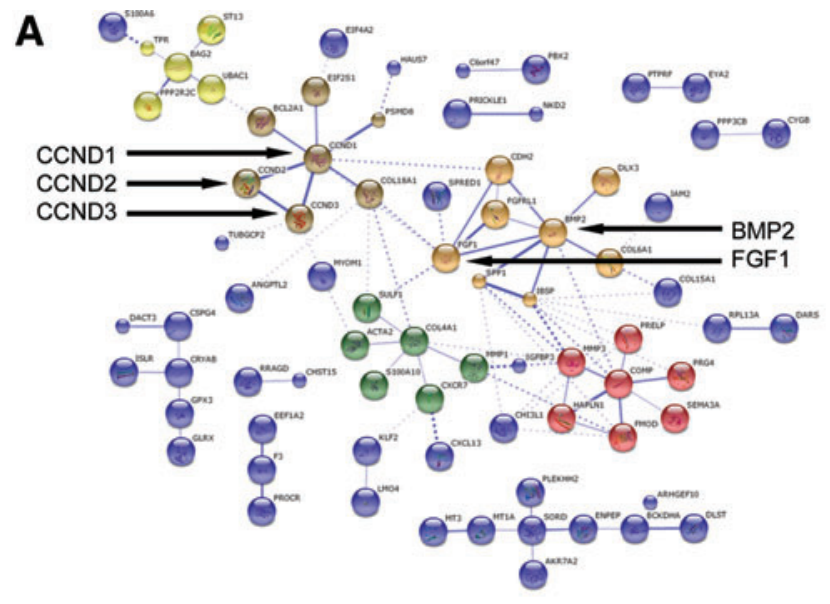

B
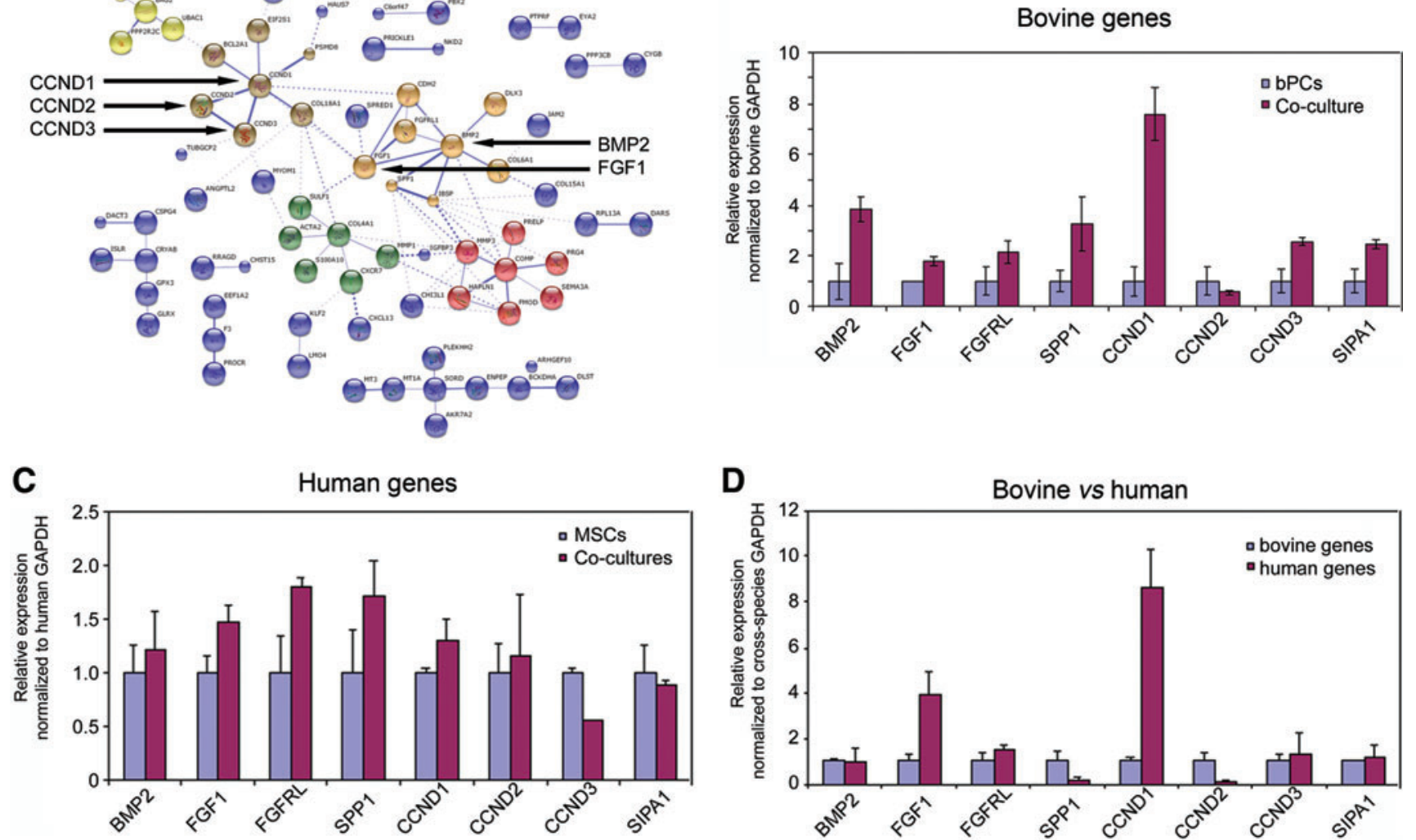

FIG. 3. Interaction networks of up-regulated genes and species-specific qPCR in xenogenic co-culture of bPCs and hMSCs. (A) The predicted interaction networks of the 180 up-regulated genes/proteins were shown. (B) 80\% of human MSCs and $20 \%$ bovine chondrocytes were co-cultured for 2 days. RNA was then isolated. Expression of bovine genes was examined by real-time RT-PCR using bovine specific primers that did not cross-react with human genes. Data are expressed as fold change relative to the expression in chondrocyte monocultures and represent the mean of three independent experiments \pm S.D. (C) Expression of human genes was also demonstrated by real-time RT-PCR using human specific primers that did not crossreact with bovine genes. Data are expressed as fold change relative to the expression in MSC monocultures and represent the mean of three independent experiments \pm S.D. (D) Expression levels of both bovine and human genes in co-culture pellets were normalized to cross-species GAPDH. Human gene expression is plotted relative to the expression of the respective bovine gene, which was set to one, and represents the mean of three independent experiments \pm S.D. bPCs, bovine primary chondrocytes. Color images available online at www.liebertpub.com/scd

5B) and hPCs in co-culture pellets and nullified the increased hPCs proliferation usually found in co-culture pellets (Fig. 5C). To analyze the role of FGF-1 more specifically, a neutralizing antibody was used to block FGF-1 activity. FGF-1 neutralizing antibodies significantly reduced proliferation of hMSCs (Fig. 5B) and hPC (Fig. 5C) also in co-culture pellets.

\section{FGF-1 in MSC CM induces hPCs proliferation}

Previously, we reported that secreted factors from CM of MSCs cultured in a monolayer increased the proliferation of hPCs in pellet culture. The amount of FGF-1 contained in CM (concentrated by ultra-filtration) was determined by ELISA (Fig. 6A). The neutralizing antibody can be effectively used to block the activity of FGF-1. Then, we performed an EdU assay to test whether FGF-1 contributed to hPCs proliferation. As shown in Fig.6B and C, pellets of hPCs cultured for 2 days in hMSCs CM (CM+Normal IgG) showed more EdU incorporation than pellets cultured in nonconditioned proliferation medium (Normal IgG), which is in line with previous observations [13]. Increased hPCs proliferation was reversed by adding anti-FGF-1 to the CM. HPCs pellets cultured in proliferation medium containing human recombinant FGF-1 (10 ng/mL rhFGF-1 + Normal IgG) and medium containing both rhFGF-1 $(10 \mathrm{ng} / \mathrm{mL})$ and anti-FGF-1 (rhFGF-1 + anti-FGF-1) served as controls to verify the positive effects of FGF-1 on the proliferation of hPCs and the neutralizing activity of the anti-FGF-1 antibody.

\section{Discussion}

Previously, we have shown that co-culture of MSCs and PC in pellets augmented cartilage matrix formation. This effect was attributed to a trophic effect of the MSCs on the chondrocytes rather than the differentiation of MSCs into chondrocytes. Furthermore, we showed that in these cocultures, MSC secreted factors that potently induced chondrocyte proliferation [13]. In this study, we have identified FGF-1 as the main MSC secreted growth factor that is responsible for this effect. We base this conclusion on the following observations: (i) FGF-1 expression was up-regulated in co-cultures predominantly in the MSCs; (ii) FGF-1 is 

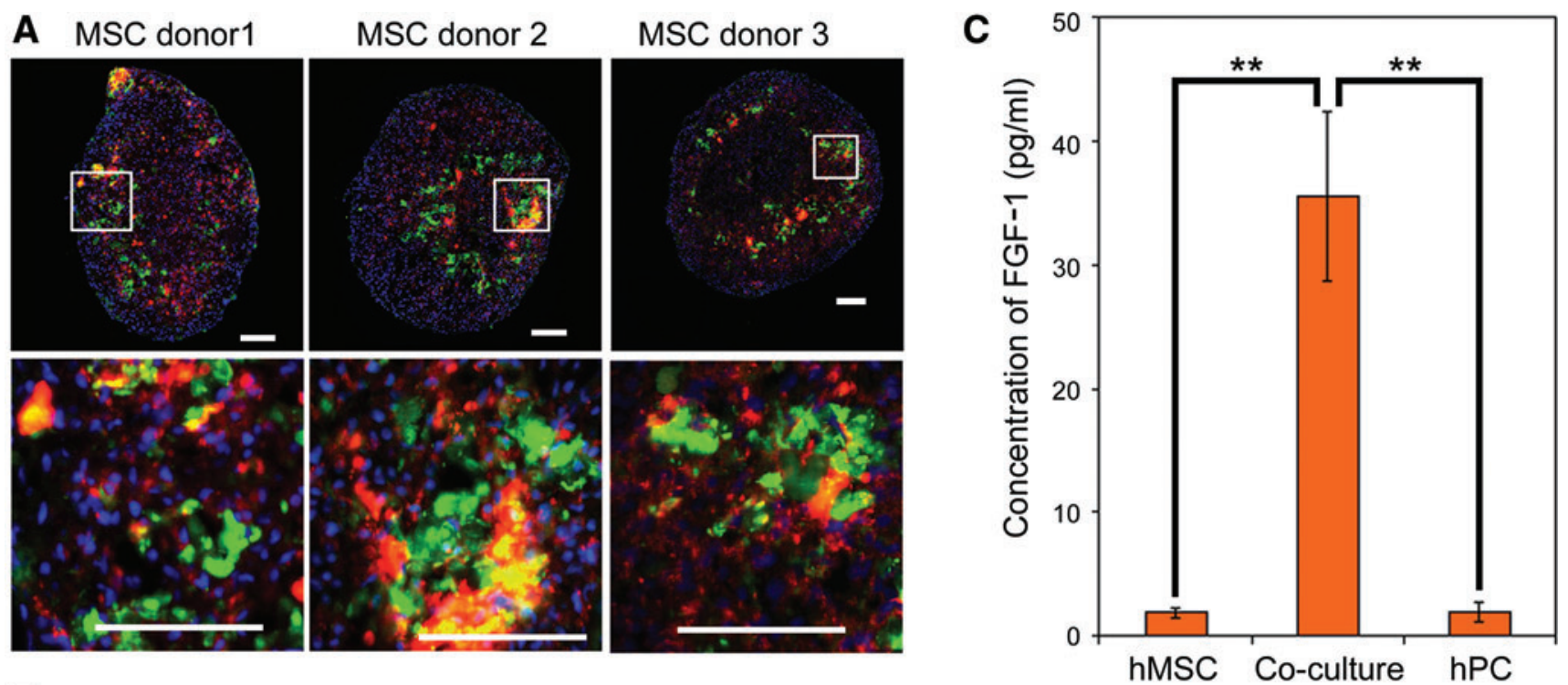

B

\begin{tabular}{cccccc}
\hline & $\begin{array}{c}\text { Total cell } \\
\text { number }\end{array}$ & $\begin{array}{c}\text { Total hPC } \\
\text { number }\end{array}$ & $\begin{array}{c}\text { Labeling } \\
\text { efficiency (\%) }\end{array}$ & $\begin{array}{c}\text { FGF-1 positive } \\
\text { area (pixels) }\end{array}$ & $\begin{array}{c}\text { FGF-1 positive } \\
\text { area in hPC (pixels) }\end{array}$ \\
\hline Donor 1 & 1529 & 265 & 19.72 & $3.4 \mathrm{E}+05$ & $9.2 \mathrm{E}+04$ \\
Donor 2 & 1737 & 295 & 16.61 & $5.1 \mathrm{E}+05$ & $1.4 \mathrm{E}+05$ \\
Donor 3 & 1738 & 306 & 18.54 & $3.1 \mathrm{E}+05$ & $8.7 \mathrm{E}+04$ \\
\hline Average & $1669 \pm 98$ & $289 \pm 17$ & $18.29 \pm 1.29$ & $3.9 \mathrm{E}+05 \pm 8.7 \mathrm{E}+04$ & $1.1 \mathrm{E}+05 \pm 2.5 \mathrm{E}+04$
\end{tabular}

FIG. 4. Expression of FGF-1 at protein level on co-culture pellets. (A) hPCs (labeled red) were co-cultured with MSCs for 2 days. Immunofluorescent staining of FGF-1 (green) was performed on mid-saggital cryo-sections, while nuclei were counterstained with DAPI. Pictures show a representative section from each donor. Double-labeled cells are shown in yellow and represent FGF-1 positive chondrocytes. Lower panels are magnifications of the boxed areas. Scale bar $=50 \mu \mathrm{m}$. (B) Quantification of FGF-1-positive area. For each donor, three pellets were analyzed. For each pellet, six sections were analyzed. Average values \pm S.D. are given. Total cell numbers, number of hPC, FGF-1-positive area (pixels), and FGF-1-positive area in hPC (pixels) were shown. Labeling efficiency was calculated by dividing the numbers of hPCs by total cell numbers. The \% of FGF positive area in MSCs was calculated as follows: $100 \% \times([F G F-1$ positive area in chondrocytes]/FGF-1 positive area). (C) Conditioned medium of co-culture and mono-culture pellets was collected at day 2 after seeding. Un-concentrated conditioned medium was used for ELISA. The concentrations of FGF-1 were represented as the mean of three donors \pm SD. Statistical analysis was performed using one-way analysis of variance. ${ }^{* *} P<0.01$. CM, conditioned medium; DAPI, 4,6diamidino-2-phenylindole; ELISA, enzyme-linked immunosorbent assay; FGF-1, fibroblast growth factor-1. Color images available online at www.liebertpub.com/scd

secreted in CM of co-culture pellets only and in CM of MSCs cultured in a monolayer; and (iii) blocking FGF-1 activity either by chemical inhibitors of the FGF-receptor signaling pathway or by an FGF-1 neutralizing antibody potently inhibited hPCs proliferation that is usually induced in co-culture pellets of MSCs and hPCs.

Many reports addressing the secretome of MSCs investigated their secretory profile at late stages of adipogenic, osteogenic, and chondrogenic differentiation [27-29]. Only a few studies explored the secretome of undifferentiated MSCs [30]. It has been shown in a proteomic study that undifferentiated MSCs secrete a number of matrix components and matrix regulators in 2D cultures [31]; however, the expression of the regulation of these proteins by cellular interactions between MSCs and other cell types is not yet investigated. The current study is one of the first to explore the response and changes in the gene expression of MSCs in co-culture with other cell types. Our study provides clear evidence that MSCs change the expression and secretion of a number of genes in response to a co-culture with other cell types.

One of the most important observations in this study is that a co-culture of MSCs and hPCs up-regulated a number of cytokines and growth factors as well as a variety of matrix remodeling proteins. Among these genes, BMP-2 and FGF-1 stood out, as their functions in chondrocyte proliferation and matrix formation had been previously demonstrated [32-34]. For a long time, BMP-2 has been used as a strong stimulator for osteogenic differentiation of stem cells [35]. In other studies, however, BMP-2 has been applied to promote the chondrogenic differentiation of MSCs as well [24,26]. Meanwhile, it is also believed that BMP-2-induced chondrogenic differentiation of MSCs will eventually lead to hypertrophy and endochondral ossification [36,37]. Besides 
A
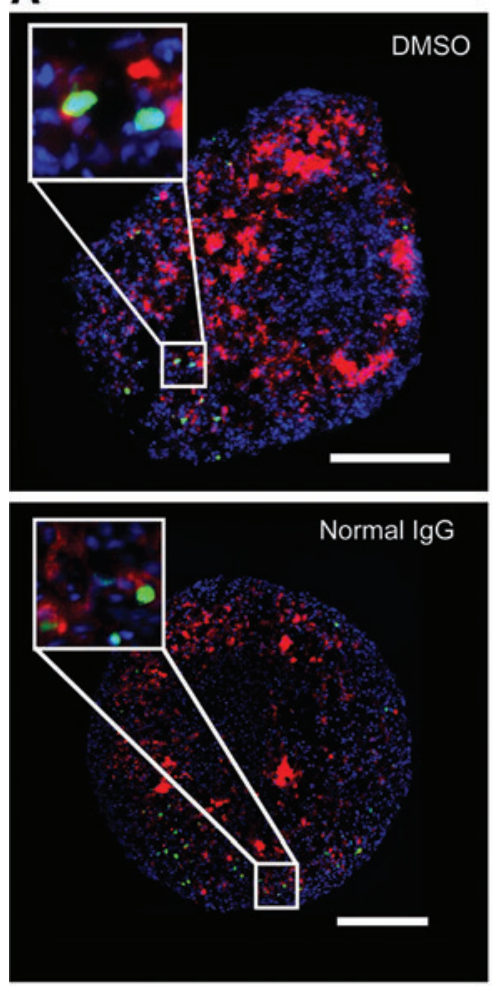

B

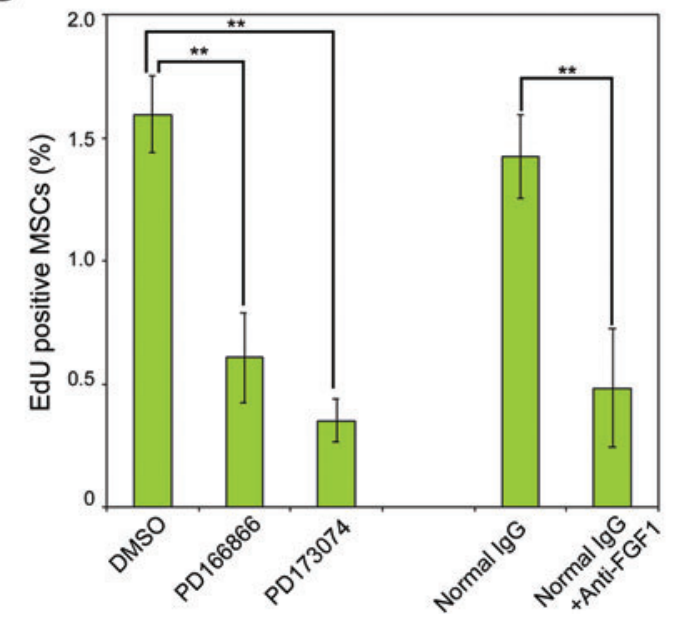

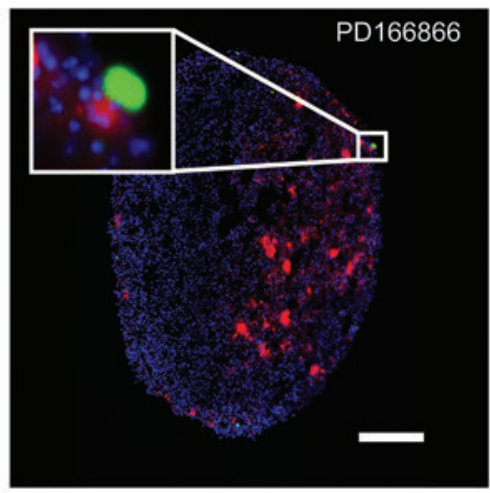
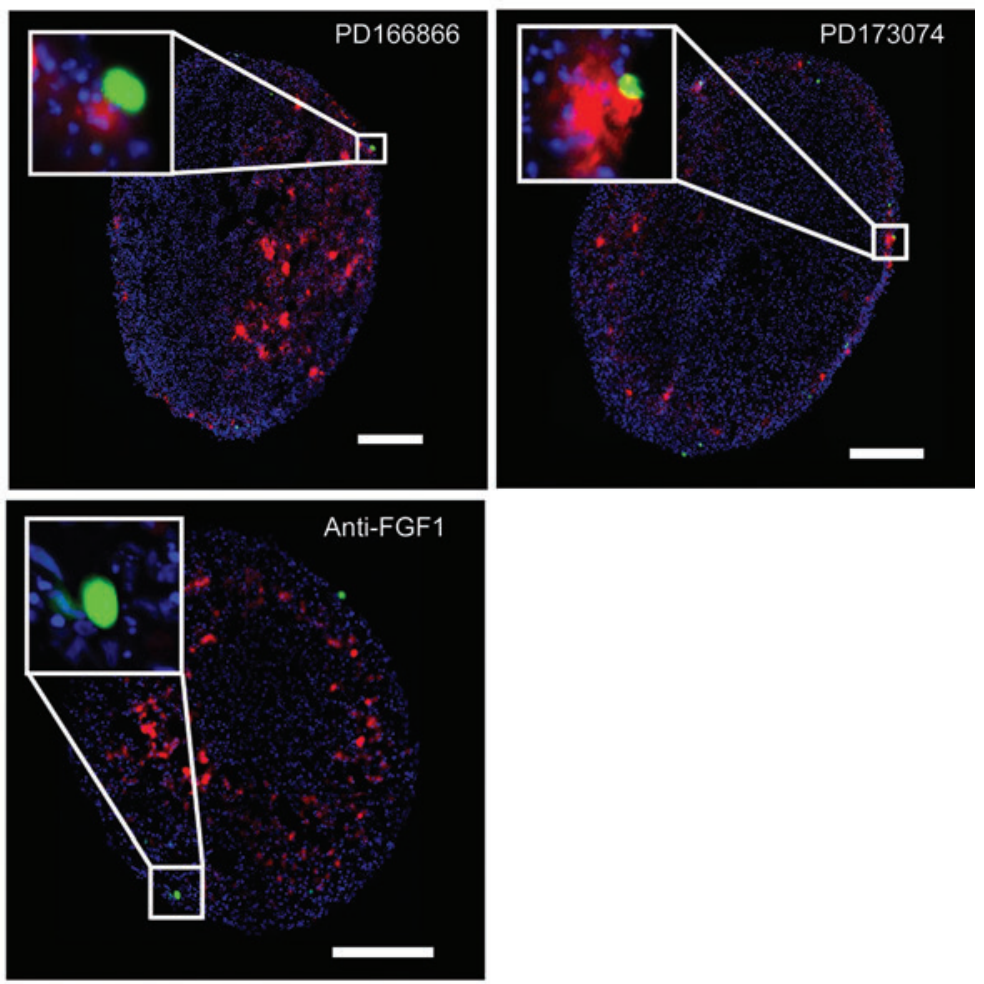

C

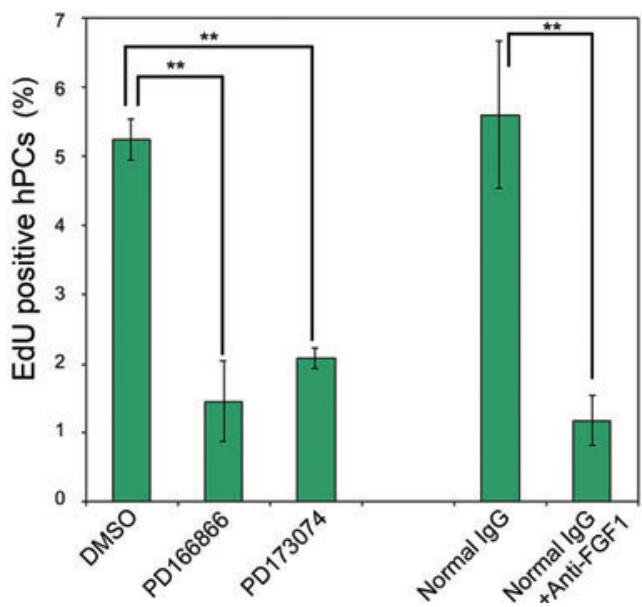

FIG. 5. Inhibition of FGF-1 signaling reduces proliferation of hPCs in co-culture. (A) EdU staining of co-culture pellets at day 2. hPC were labeled with CM-DiI (red). EdU incorporation into newly synthesized DNA was visualized by Alexa 488 (green). Nuclei were counterstained with Hoechst 33342 (blue). FGF-1 signaling was inhibited by either specific FGF-receptor inhibitors (500 nM of PD166866 and $500 \mathrm{nM}$ of PD173074) or an FGF-1 neutralizing antibody $(5 \mu \mathrm{g} / \mathrm{mL})$. DMSO was used as vehicle for chemical inhibitors, while normal goat IgG $(5 \mu \mathrm{g} / \mathrm{mL})$ served as control for neutralizing antibodies. Three donor pairs of MSCs and hPCs were analyzed. A representative example is shown for each condition Scale bar $=100 \mu \mathrm{m}$. (B, C) Quantification of EdU-positive MSCs (B) or hPCs (C) in co-culture pellets. Data represent the average from 3 MSC donors, with each measured in triplicate \pm S.D. ${ }^{* *} P<0.01$. Color images available online at www.liebertpub.com/scd

BMP-2's contribution to matrix formation, there are a few reports studying its function in chondrocyte proliferation $[34,38]$. However, qPCR data from the xenogenic co-culture model indicated that expression of BMP-2 appeared to be increased predominantly in hPCs but not in MSCs. Therefore, BMP-2 is very unlike to be a decisive trophic factor produced by MSCs in co-culture pellets, which is the main focus of this study. It is feasible though that up-regulated
BMP-2 expression in hPCs induced by the MSCs in co-culture is at least in part responsible for increased matrix formation in co-culture pellets. This is the subject of further studies.

We next paid our attention to the effects of FGF-1 in coculture. FGF-1 belongs to the fibroblast growth factor super family, which consists of 22 genes in humans and mice [39]. Similar to other members in the FGF family, FGF-1 is 

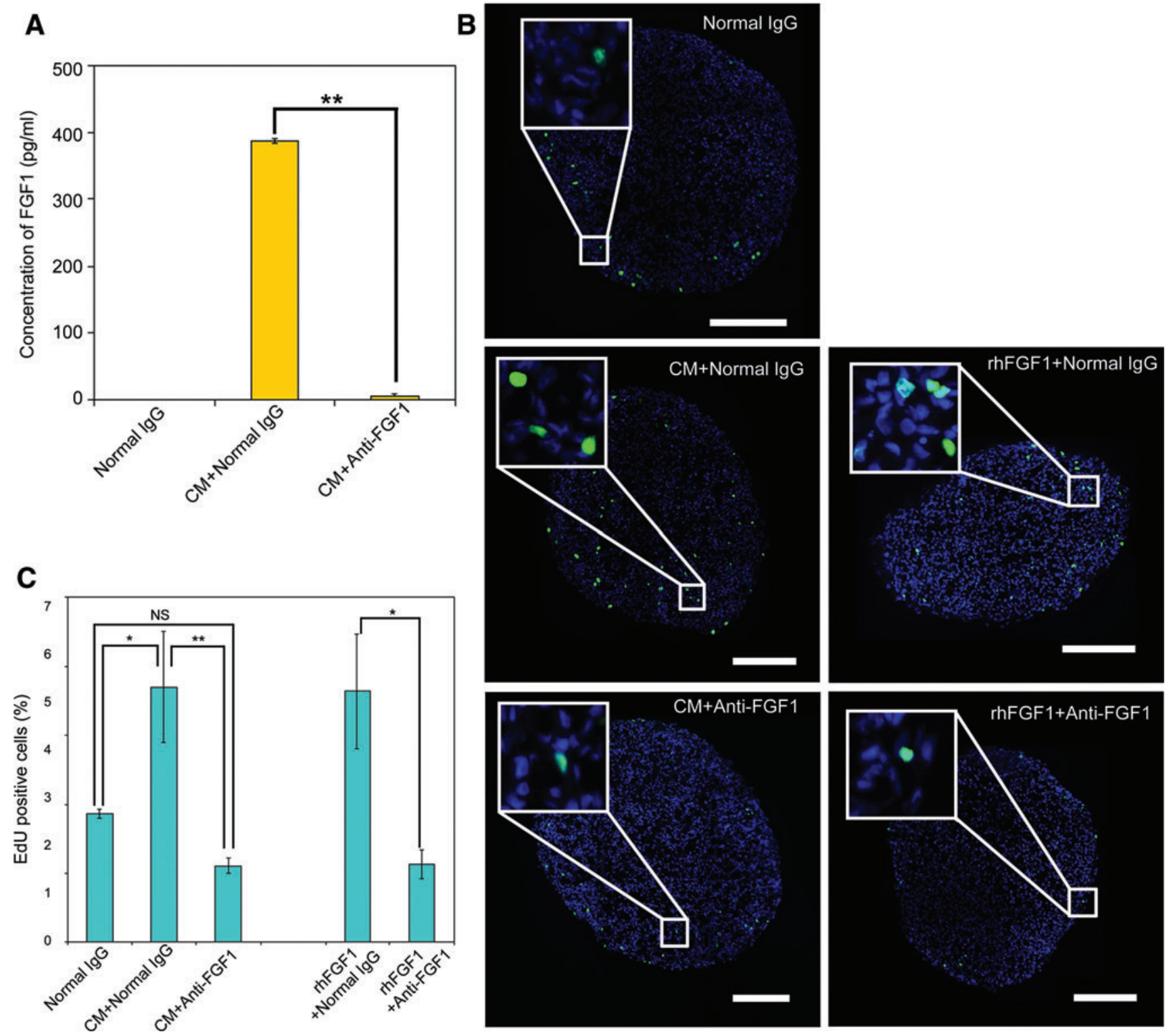

FIG. 6. MSC-secreted FGF-1 promotes hPCs proliferation. (A) The concentration of FGF-1 in the CM (concentrated by untrafiltration) of hMSCs cultured in a monolayer was quantified by ELISA. CM was collected from three hMSCs donors. Medium was pooled and concentrated for ELISA and EdU assays. (B) EdU staining was performed at day 2 to show proliferating cells in pellets of chondrocytes cultured in MSC CM. EdU incorporation into newly synthesized DNA was visualized by Alexa 488 (green). Nuclei were counterstained with Hoechst 33342 (blue). Activity of FGF-1 was blocked by a neutralizing antibody $(5 \mu \mathrm{g} / \mathrm{mL})$. Normal $\operatorname{IgG}(5 \mu \mathrm{g} / \mathrm{mL})$ and rhFGF-1 $(10 \mathrm{ng} / \mathrm{mL})$ served as a negative and positive control, respectively. Scale bar $=100 \mu \mathrm{m}$. (C) Quantification of EdU-positive chondrocytes. Data represent the mean of 3 chondrocyte donors \pm S.D. $P$ values were calculated with Student's $t$-test. ${ }^{*} P<0.05$. ${ }^{* *} P<0.01$. Color images available online at www.liebertpub.com/scd

ubiquitously involved in vertebrate embryonic and fetal development, as well as in many physiological processes in adults and pathological conditions [40]. It functions by activating a family of tyrosine kinase cell-surface receptors (FGFRs). Unlike FGF-2, FGF-1 is synthesized as one $17.5 \mathrm{kD}$ cytosolic protein [41]. It is expressed in normal physiological conditions but secreted in response to stress, such as injuries and heat shock [42]. There are reports claiming that FGF-1 could be secreted from chondrocytes, chondrogenic precursors, and macrophages to stimulate the proliferation of immature chondrocytes, and to indirectly accelerate their maturation and deposition of cartilage matrix proteins [25].
Our results also showed that FGF-1 was expressed at low levels in hPCs, and its expression modestly increased in co-culture with MSCs. The dominant sources of FGF-1 in co-culture pellets were, however, the MSCs, as shown by immunofluorescent staining in combination with cell tracking and species-specific PCR in xenogenic co-cultures.

Traditionally, scientists believed that FGF-2 might play a more important role in the proliferation of chondrocytes than does FGF-1 [32]. Many efforts have been made to study the molecular signals involved in FGF-2 induced proliferation of chondrocytes [43-45], with the hope of preventing the formation of fibrous cartilage tissue caused by FGF-2 treatment 
$[46,47]$. Our data uncover a positive role of FGF-1 in proliferation of hPCs, at least in co-culture with MSCs. Our qPCR data obtained from the xenogenic co-culture models as well as results of immunofluorescent staining clearly showed that the expression of FGF-1 in the co-culture pellets is predominantly from MSCs. Combined with our observations that blockade of FGF-1 activity either by inhibitors of FGFRsignaling or by a neutralizing antibody inhibited hPCs proliferation in co-culture pellets and that neutralizing antibodies blocked hPCs proliferation induced by MSC CM, our study identifies FGF-1 as the MSC secreted factor that is responsible for the stimulation of hPCs proliferation in cocultures. Even though our data suggested a positive role of FGF-1 in co-culture pellets, recombinant protein may not be good to replace MSCs in the co-culture system, as secreted factors from MSCs may decrease the deposition of the cartilaginous ECM, including GAGs and collagen type II from articular chondrocytes in a long-term culture [48]. Based on our previous studies, we believe that cell-cell contact between MSCs and chondrocytes in the co-culture system is crucial for maintaining chondrogenic phenotypes.

Another interesting finding in this article is the location of the cells expressing FGF-1 in co-culture pellets, as indicated by immunofluorescent staining. In line with the expression of FGF-1 at mRNA level in hPCs, some hPCs stained positive with FGF-1 antibodies. However, staining in MSCs was more abundant. Interestingly, the most intense FGF-1 staining was found in MSCs that were in close vicinity or even direct contact with hPCs. More distant MSCs without physical contacts with hPCs either expressed FGF-1 at a low level or did not express FGF-1 at all. This implies that the enhancement of FGF-1 expression in co-culture pellets is very likely due to an as yet unknown effect of the hPCs on the MSCs. This may either involve a secreted factor or as FGF-1 expressing MSCs are invariably in close vicinity of the chondrocytes signaling via direct cell-cell contacts. We are currently exploring both options. Combined with the fact that FGF-1 concentration increased dramatically in the CM of co-culture pellets when compared with mono-cultures, we also concluded that not only expression but also secretion of FGF-1 is increased by the cross-talk between MSCs and hPCs. From literature, it can be deduced that both cells secrete a wide range of growth factors, cytokines, and extracellular matrix components into their surrounding environment [31]. Some of these molecules may form a feedback loop that stimulates the expression of FGF-1. There are numerous examples of the regulatory effect of MSCs in inflammation. In many cases, the MSCs create a feedback loop with other cell types to activate or inhibit signaling pathways [49]. In this study, we now expand this to mutual cross-talk between MSCs and chondrocytes.

In conclusion, our data have identified FGF-1 as an MSC secreted factor whose expression increased on co-culture with hPCs. Increased FGF-1 expression potently stimulated hPCs proliferation. As far as we know, this study is one of the first that is dedicated to the analysis of reciprocal changes in gene expression in co-culture pellets of MSCs with other cell types. It provides clear evidence for a mutual relationship between MSCs and hPCs. It has been proposed that an intra-articular injection of MSCs might be a treatment option for osteoarthritis. This is currently under investigation in clinical trials [50]. Our study may provide insights on how
MSCs exert such beneficial effects on diseased cartilage. In addition, besides FGF-18, which is explored for clinical application in osteoarthritis, our study identifies FGF-1 as a potential therapeutic agent in osteoarthritis.

\section{Acknowledgments}

The authors gratefully acknowledge the financial support of the TeRM Smart Mix Program of The Netherlands Ministry of Economic Affairs and The Netherlands Ministry of Education, Culture, and Science. They are grateful to Jacqueline Plass for her technical support. They also thank Ivy Wang for language editing of the article.

\section{Author Disclosure Statement}

No competing financial interests exist.

\section{References}

1. Alford JW and BJ Cole. (2005). Cartilage restoration, part 1: basic science, historical perspective, patient evaluation, and treatment options. Am J Sports Med 33:295-306.

2. Alford JW and BJ Cole. (2005). Cartilage restoration, part 2: techniques, outcomes, and future directions. Am J Sports Med 33:443-460.

3. Wakitani S, K Imoto, T Yamamoto, M Saito, N Murata and M Yoneda. (2002). Human autologous culture expanded bone marrow mesenchymal cell transplantation for repair of cartilage defects in osteoarthritic knees. Osteoarthritis Cartilage 10:199-206.

4. Murphy JM, DJ Fink, EB Hunziker and FP Barry. (2003). Stem cell therapy in a caprine model of osteoarthritis. Arthritis Rheum 48:3464-3474.

5. Gonzalez MA, E Gonzalez-Rey, L Rico, D Buscher and M Delgado. (2009). Treatment of experimental arthritis by inducing immune tolerance with human adipose-derived mesenchymal stem cells. Arthritis Rheum 60:1006-1019.

6. Augello A, R Tasso, SM Negrini, R Cancedda and G Pennesi. (2007). Cell therapy using allogeneic bone marrow mesenchymal stem cells prevents tissue damage in collageninduced arthritis. Arthritis Rheum 56:1175-1186.

7. Nemeth K, A Leelahavanichkul, PS Yuen, B Mayer, A Parmelee, K Doi, PG Robey, K Leelahavanichkul, BH Koller, et al. (2009). Bone marrow stromal cells attenuate sepsis via prostaglandin E(2)-dependent reprogramming of host macrophages to increase their interleukin-10 production. Nat Med 15:42-49.

8. Ter Huurne M, R Schelbergen, R Blattes, A Blom, W de Munter, L Grevers, J Jeanson, D Noel, L Casteilla, et al. (2012). Anti-inflammatory and chondro protective effects of intra-articular injection of adipose-derived stem cells in experimental osteoarthritis. Arthritis Rheum 64:3604-3613.

9. MacDonald GI, A Augello and C De Bari. (2011). Role of mesenchymal stem cells in reestablishing immunologic tolerance in autoimmune rheumatic diseases. Arthritis Rheum 63:2547-2557.

10. McGonagle D, C De Bari, P Arnold and E Jones. (2007). Lessons from musculoskeletal stem cell research: the key to successful regenerative medicine development. Arthritis Rheum 56:714-721.

11. Hendriks JAA, RL Miclea, R Schotel, E de Bruijn, L Moroni, M Karperien, J Riesle and CA van Blitterswijk. (2010). Primary chondrocytes enhance cartilage tissue formation upon 
co-culture with a range of cell types. Soft Matter 6:50805088.

12. Acharya C, A Adesida, P Zajac, M Mumme, J Riesle, I Martin and A Barbero. (2012). Enhanced chondrocyte proliferation and mesenchymal stromal cells chondrogenesis in coculture pellets mediate improved cartilage formation. J Cell Physiol 227:88-97.

13. Wu L, JC Leijten, N Georgi, JN Post, CA van Blitterswijk and M Karperien. (2011). Trophic effects of mesenchymal stem cells increase chondrocyte proliferation and matrix formation. Tissue Eng Part A 17:1425-1436.

14. Wu L, HJ Prins, M Helder, $C$ van Blitterswijk and M Karperien. (2012). Trophic effects of mesenchymal stem cells in chondrocyte co-cultures are independent of culture conditions and cell sources. Tissue Eng Part A 18:1542-1551.

15. Walter MN, KT Wright, HR Fuller, S MacNeil and WE Johnson. (2010). Mesenchymal stem cell-conditioned medium accelerates skin wound healing: an in vitro study of fibroblast and keratinocyte scratch assays. Exp Cell Res 316:1271-1281.

16. Yoon BS, JH Moon, EK Jun, J Kim, I Maeng, JS Kim, JH Lee, CS Baik, A Kim, et al. (2010). Secretory profiles and wound healing effects of human amniotic fluid-derived mesenchymal stem cells. Stem Cells Dev 19:887-902.

17. Caplan AI and JE Dennis. (2006). Mesenchymal stem cells as trophic mediators. J Cell Biochem 98:1076-1084.

18. da Silva Meirelles L, AI Caplan and NB Nardi. (2008). In search of the in vivo identity of mesenchymal stem cells. Stem Cells 26:2287-2299.

19. Moreira Teixeira LS, J Leijten, J Sobral, R Jin, AA van Apeldoorn, J Feijen, C van Blitterswijk, PJ Dijkstra and M Karperien. (2012). High throughput generated micro-aggregates of chondrocytes stimulate cartilage formation in vitro and in vivo. Eur Cell Mater 23:387-399.

20. Wu L, X Cai, H Dong, W Jing, Y Huang, X Yang, Y Wu and $Y$ Lin. (2010). Serum regulates adipogenesis of mesenchymal stem cells via MEK/ERK-dependent PPARgamma expression and phosphorylation. J Cell Mol Med 14:922-932.

21. Leijten JC, J Emons, C Sticht, S van Gool, E Decker, A Uitterlinden, G Rappold, A Hofman, F Rivadeneira, et al. (2012). Gremlin 1, frizzled-related protein, and Dkk-1 are key regulators of human articular cartilage homeostasis. Arthritis Rheum 64:3302-3312.

22. Szklarczyk D, A Franceschini, M Kuhn, M Simonovic, A Roth, P Minguez, T Doerks, M Stark, J Muller, et al. (2011). The STRING database in 2011: functional interaction networks of proteins, globally integrated and scored. Nucleic Acids Res 39:D561-D568.

23. Abramoff MD, PJ Magelhaes and SJ Ram. (2004). Image processing with ImageJ. Biophotonics Int 11:36-42.

24. Kurth T, E Hedbom, N Shintani, M Sugimoto, FH Chen, M Haspl, S Martinovic and EB Hunziker. (2007). Chondrogenic potential of human synovial mesenchymal stem cells in alginate. Osteoarthritis Cartilage 15:1178-1189.

25. Bolander ME. (1992). Regulation of fracture repair by growth factors. Proc Soc Exp Biol Med 200:165-170.

26. Noth U, L Rackwitz, A Heymer, M Weber, B Baumann, A Steinert, N Schutze, F Jakob and J Eulert. (2007). Chondrogenic differentiation of human mesenchymal stem cells in collagen type I hydrogels. J Biomed Mater Res A 83:626-635.

27. Alvarez-Llamas G, E Szalowska, MP de Vries, D Weening, K Landman, A Hoek, BH Wolffenbuttel, H Roelofsen and RJ Vonk. (2007). Characterization of the human visceral adipose tissue secretome. Mol Cell Proteomics 6:589-600.
28. Ji YH, JL Ji, FY Sun, YY Zeng, XH He, JX Zhao, Y Yu, SH Yu and W Wu. (2010). Quantitative proteomics analysis of chondrogenic differentiation of $\mathrm{C} 3 \mathrm{H} 10 \mathrm{~T} 1 / 2$ mesenchymal stem cells by iTRAQ labeling coupled with on-line twodimensional LC/MS/MS. Mol Cell Proteomics 9:550-564.

29. Chiellini C, O Cochet, L Negroni, M Samson, M Poggi, G Ailhaud, MC Alessi, C Dani and EZ Amri. (2008). Characterization of human mesenchymal stem cell secretome at early steps of adipocyte and osteoblast differentiation. BMC Mol Biol 9:26.

30. Choi YA, J Lim, KM Kim, B Acharya, JY Cho, YC Bae, HI Shin, SY Kim and EK Park. (2010). Secretome analysis of human BMSCs and identification of SMOC1 as an important ECM protein in osteoblast differentiation. J Proteome Res 9:2946-2956.

31. Polacek M, JA Bruun, J Elvenes, Y Figenschau and I Martinez. (2011). The secretory profiles of cultured human articular chondrocytes and mesenchymal stem cells: implications for autologous cell transplantation strategies. Cell Transplant 20:1381-1393.

32. Ornitz DM. (2005). FGF signaling in the developing endochondral skeleton. Cytokine Growth Factor Rev 16:205-213.

33. Shea CM, CM Edgar, TA Einhorn and LC Gerstenfeld. (2003). BMP treatment of C3H10T1/2 mesenchymal stem cells induces both chondrogenesis and osteogenesis. J Cell Biochem 90:1112-1127.

34. Shu B, M Zhang, R Xie, M Wang, H Jin, W Hou, D Tang, SE Harris, Y Mishina, et al. (2011). BMP2, but not BMP4, is crucial for chondrocyte proliferation and maturation during endochondral bone development. J Cell Sci 124:3428-3440.

35. Lin $\mathrm{Y}, \mathrm{W}$ Tang, L Wu, W Jing, X Li, Y Wu, L Liu, J Long and W Tian. (2008). Bone regeneration by BMP-2 enhanced adipose stem cells loading on alginate gel. Histochem Cell Biol 129:203-210.

36. Carlberg AL, B Pucci, R Rallapalli, RS Tuan and DJ Hall. (2001). Efficient chondrogenic differentiation of mesenchymal cells in micromass culture by retroviral gene transfer of BMP-2. Differentiation 67:128-138.

37. Steinert AF, B Proffen, M Kunz, C Hendrich, SC Ghivizzani, U Noth, A Rethwilm, J Eulert and CH Evans. (2009). Hypertrophy is induced during the in vitro chondrogenic differentiation of human mesenchymal stem cells by bone morphogenetic protein-2 and bone morphogenetic protein- 4 gene transfer. Arthritis Res Ther 11:R148.

38. Li X, J Peng, M Wu, H Ye, C Zheng, G Wu, H Xu, X Chen and X Liu. (2011). BMP2 promotes chondrocyte proliferation via the Wnt/beta-catenin signaling pathway. Mol Med Report 4:621-626.

39. Itoh $\mathrm{N}$ and DM Ornitz. (2004). Evolution of the Fgf and Fgfr gene families. Trends Genet 20:563-569.

40. Bottcher RT and C Niehrs. (2005). Fibroblast growth factor signaling during early vertebrate development. Endocr Rev 26:63-77.

41. Friesel RE and T Maciag. (1995). Molecular mechanisms of angiogenesis: fibroblast growth factor signal transduction. FASEB J 9:919-925.

42. Jackson A, S Friedman, X Zhan, KA Engleka, R Forough and T Maciag. (1992). Heat shock induces the release of fibroblast growth factor 1 from NIH 3T3 cells. Proc Natl Acad Sci U S A 89:10691-10695.

43. Khan IM, EA Palmer and CW Archer. (2010). Fibroblast growth factor-2 induced chondrocyte cluster formation in experimentally wounded articular cartilage is blocked by soluble Jagged-1. Osteoarthritis Cartilage 18:208-219. 
44. Khan IM, SL Evans, RD Young, EJ Blain, AJ Quantock, N Avery and CW Archer. (2011). Fibroblast growth factor 2 and transforming growth factor beta1 induce precocious maturation of articular cartilage. Arthritis Rheum 63:3417-3427.

45. Nishida T, S Kubota, E Aoyama, D Janune, A Maeda and M Takigawa. (2011). Effect of CCN2 on FGF2-induced proliferation and MMP9 and MMP13 productions by chondrocytes. Endocrinology 152:4232-4241.

46. Yan D, D Chen, SM Cool, AJ van Wijnen, K Mikecz, G Murphy and HJ Im. (2011). Fibroblast growth factor receptor 1 is principally responsible for fibroblast growth factor 2induced catabolic activities in human articular chondrocytes. Arthritis Res Ther 13:R130.

47. Handorf AM and WJ Li. (2011). Fibroblast growth factor-2 primes human mesenchymal stem cells for enhanced chondrogenesis. PLoS One 6:e22887.

48. Xu L, Q Wang, F Xu, Z Ye, Y Zhou and WS Tan. (2013). Mesenchymal stem cells downregulate articular chondrocyte differentiation in noncontact coculture systems: implications in cartilage tissue regeneration. Stem Cells Dev [Epub ahead of print]; DOI: 10.1089/scd.2012.0605.

49. Prockop DJ and JY Oh. (2012). Mesenchymal stem/stromal cells (MSCs): role as guardians of inflammation. Mol Ther 20:14-20.
50. Kasemkijwattana C, S Hongeng, S Kesprayura, V Rungsinaporn, K Chaipinyo and K Chansiri. (2011). Autologous bone marrow mesenchymal stem cells implantation for cartilage defects: two cases report. J Med Assoc Thai 94:395-400.

Address correspondence to: Prof. Marcel Karperien Department of Development BioEngineering MIRA-Institute for Biomedical Technology and Technical Medicine University of Twente P.O. Box 217 7500AE Enschede The Netherlands

E-mail: h.b.j.karperien@utwente.nl

Received for publication March 2, 2013

Accepted after revision April 2, 2013

Prepublished on Liebert Instant Online April 4, 2013 